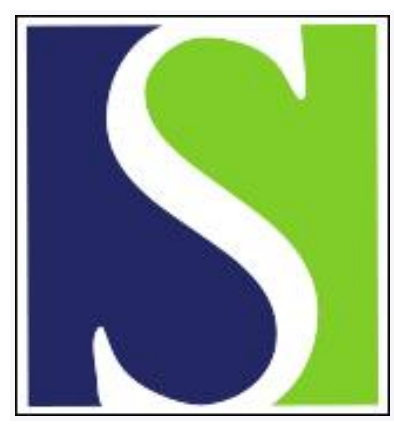

Scand J Work Environ Health 1979;5(4):368-374

https://doi.org/10.5271/sjweh.2644

Issue date: Dec 1979

Blood flow in the contralateral hand during vibration and hand grip contractions of lumberjacks.

by Färkkilä M, Pyykkö I

Key terms: blood flow; contralateral hand; contralateral vibration; hand; hand grip; hand grip contraction; lumberjack; vibration; vibration disease

This article in PubMed: www.ncbi.nlm.nih.gov/pubmed/538428

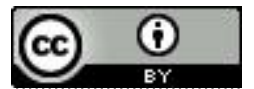




\title{
Blood flow in the contralateral hand during vibration and hand grip contractions. of lumberjacks
}

\author{
by MARKUS FÄRKKILÄ, M.D., and ILMARI PYYKKÖ, M.D. ${ }^{1}$
}

\begin{abstract}
FARKKILA, M. and PYYKKÖ, I. Blood flow in the contralateral hand during vibration and hand grip contractions of lumberjacks. Scand. j. work environ. \& health 5 (1979) 368-374. Pulse wave changes were examined among 63 professional lumberjacks. The tests were carried out in connection with an annual health examination. A photoelectric plethysmographic method was used to measure pulse wave changes during contralateral muscle work and vibration exposure from a dynamic shaker with a strain-gauge dynamometer. The relative changes in pulse wave amplitude were counted, and the changes were classified as dilatations, constrictions, or constant pulse wave amplitude. Contralateral muscle work caused vasodilatation, but vibration exposure could cause vasoconstrictions in the right hand. Most of the vasospasms were recorded at 60 and $100 \mathrm{~Hz}$. The strongest vasospasms were seen at $200 \mathrm{~Hz}$. The occurrence of vasospasms in the contralateral hand correlated with the severity of white finger symptoms rated according to an index for traumatic vasospastic disease.
\end{abstract}

Key words: blood flow, contralateral vibration, hand grip contractions, vibration disease.

Occupational exposure to vibration causes disturbances in the circulation of fingers called vibration-induced white fingers (VWF) (21). The mechanism of the Raynaud's phenomenon of occupational origin has been studied in many investigations, but it still remains obscure. Lewis (8) suggested that vibration produces a local change in the sympathetic vasoconstrictor nerve endings. Marshall et al. (10) created

1 Department of Physiology, University of Helsinki, Helsinki, Finland.

Reprint requests to: Dr. Markus Färkkilä, Department of Physiology, University of Helsinki, Siltavuorenpenger $20 \mathrm{~J}$, SF-00170 Helsinki 17, Finland. a theory of nerve damage as the primary cause of vasospastic symptoms. Magos and Okos (9) suggested that cold-induced vasodilatation would be disturbed among patients with vibration-induced white fingers. Steward and Goda (20) suggested that callosities in fingers and palms could cause disturbances in circulation and white fingers. We $(7,19)$ have presented a theory of central sympathetic vasoconstrictor reflex triggered by high frequency vibration. According to this theory the Pacinian corpuscles act as vibration receptors and activate a vasoconstrictor reflex arch. Moreover, we have recently presented evidence that, in addition to the mechanism that leads to vasospastic symptoms, 
a different mechanism causes symptoms in the neuromuscular system of lumberjacks (4).

For a clarification of the role of central reflex mechanisms it would be useful to know what effects vibration exposure of one arm has on the contralateral arm and hand. Nasu (15) examined contralateral skin temperature during vibration exposure and suggested that vibration caused a contralateral decrease in the skin temperature or a delay in the recovery of skin temperature after vibration exposure. $\mathrm{He}$ suggested that the decrease in skin temperature was part of the tonic vibration reflex. Objective recording of the circulation in the fingers of lumberjacks can reveal a decrease in the circulation of the palm and fingers during rest or during vibration and cold provocation $(3,13,16$, 17).

The purpose of this study was to record changes in blood flow in the hand contralateral to the vibrated and working hand. The idea was to determine whether vibration can cause contralateral changes in circulation, a phenomenon which would support the theory of central vasoconstrictive reflex as the origin of VWF in vibration disease.

\section{SUBJECTS}

This examination was carried out in northern Finland during the annual health examination for lumberjacks. For this study we selected men who had sawn over $1,500 \mathrm{~h}$, who did not have primary Raynaud's disease, and who did not have acute injuries of the hands. A total of 88 lumberjacks were examined in the health examination. Sixty-three were tested in this study. Men with diabetes mellitus, arterial hypertension, or reasons for secondary Raynaud's phenomena other than vibration were excluded. The mean age of the lumberjacks was $39.7 \pm 7.2$ years, and the mean exposure to chain saw vibration was $10,100 \mathrm{~h}$ (range 1,500-26,800 h).

\section{METHODS}

To evoke vibration in the hand, we used a dynamic shaker (Ling 403). For the measurement of grip force, the handle of the shaker consisted of two metal bars (diameter $25 \mathrm{~mm}$, length $140 \mathrm{~mm}$ ) with strain gauges (Honeywell-Selcom). The vibrator was driven by sinusoidal voltage from a power amplifier (Ling TPO 300). The acceleration level and frequency were changed step by step in the course of the test. Acceleration levels (root-meansquare values) of $5 \mathrm{~g}$ were used at frequencies of 30 and $60 \mathrm{~Hz}$, and $10 \mathrm{~g}$ at frequencies of 100,200 , and $400 \mathrm{~Hz}$. The test subject sat on a chair with his right hand resting on the table and his left hand compressing the handle. The pulse wave was recorded from the resting right hand while the left hand was working.

The subjects compressed the handle maximally in pace with the strokes of a metronome. The subjects compressed for $2.5 \mathrm{~s}$, and then relaxed the hand for another $2.5 \mathrm{~s}$, and so on, for $5 \mathrm{~min}$. This test was repeated six times, once without vibration and once with each of the following vibration frequencies: $30,60,100$, 200 and $400 \mathrm{~Hz}$. The interval between the tests was $6 \mathrm{~min}$. The starting frequency was decided by lot. The different frequencies were tested in a randomized order. To record the pulse wave, a locally constructed photoelectric plethysmograph was used with the transducer placed on the nail-fingerpad region of the third finger. The amplified signals of pulse plethysmography were recorded with an ink-writer (Watanabe H611).

We assessed the mean pulse amplitude separately in the beginning and at the end of each minute by fitting a line visually through approximately 10 pulse peaks. A change in pulse amplitude was indicated by a difference larger than $25 \%$ between the levels of these two lines; smaller changes were not taken into account.

We classified the subjects according to the pulse wave responses seen in the right hand. Lumberjacks who experienced vasodilatations only comprised the first group. For the second group we selected men who did not show any change in pulse wave amplitude. In the third group were 
the lumberjacks who experienced both vasodilatations and vasospasms, and the fourth group consisted of men who showed vasospasms only.

The statistical significance of the differences between the groups were tested with Students t-test for unpaired data.

\section{RESULTS}

In this work we looked for vasodilatations in the finger pulse plethysmography of the hand contralateral to the working hand. These vasodilatations were seen in $75 \%$ of the examined lumberjacks. A recording of the pulse wave during a vasodilatation in the right hand is seen in fig. 1. During muscle work in the left arm the pulse wave gradually increased. This change occurred both without vibration and during vibration. The vasodilatation effect did not depend on the frequency of vibration. Sixty percent of the total number of vasodilatations happened during the first 2 min. The number of vasoconstrictions was nearly the same at every minute.

An example of a vasoconstriction in the right hand is seen in fig. 2. In the test we recorded 56 vasospasms, and $41.2 \%$ of the examined lumberjacks had vasospasms in these tests. The number and strength of the vasospasms were analyzed, and in fig. 3 the division of vasospasms is presented according to the different frequencies. Most of the vasospasms occurred at fre-

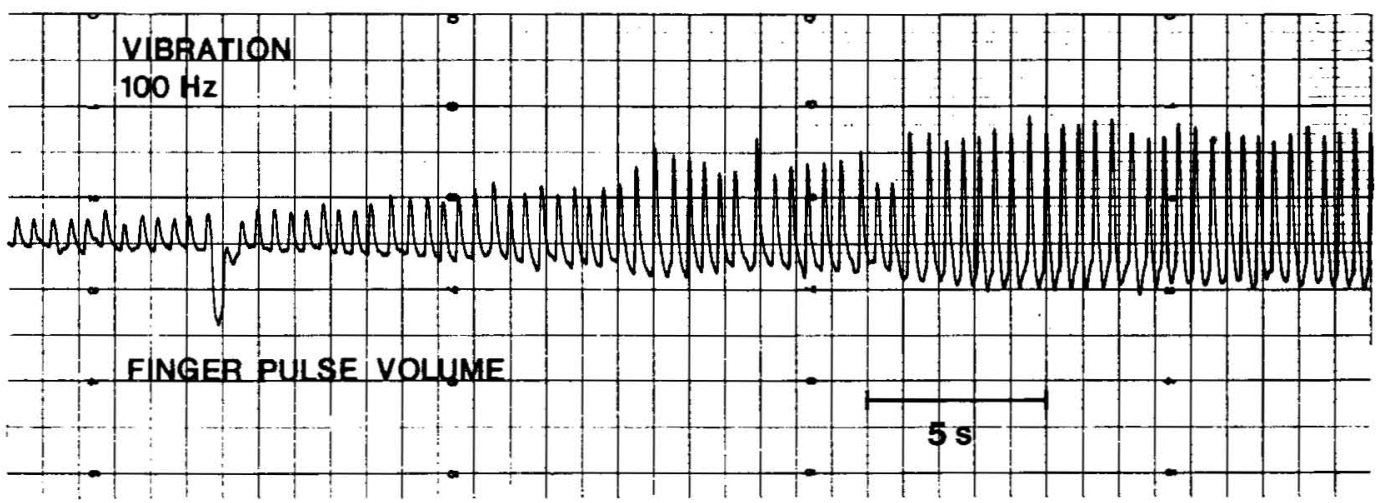

Fig. 1. Pulse wave recording from the right hand during the third minute. The lumberjack had had numb hands but never attacks of white fingers. Age 43 years, sawing time 6,000 $\mathrm{h}$.

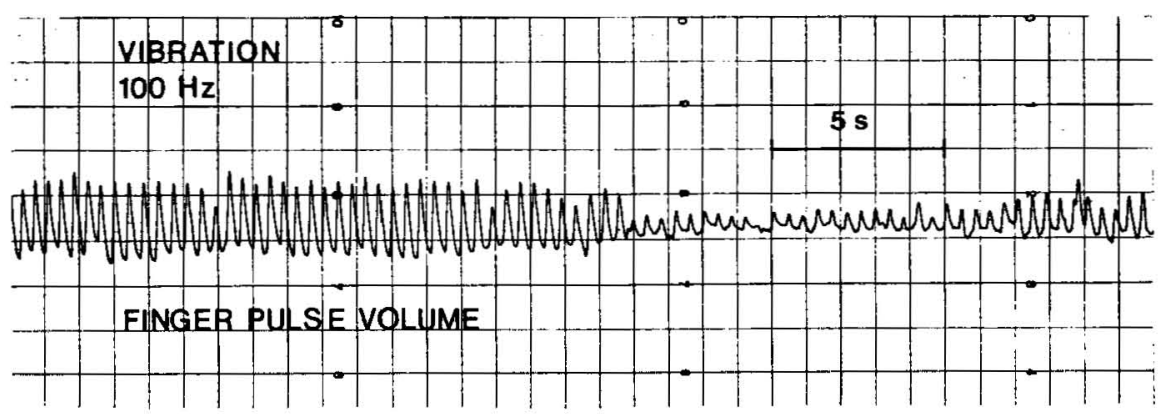

Fig. 2. Pulse wave recording from the right hand at the end of the fifth minute. The lumberjack had vibration-induced white fingers but no numbness or subjective decrease in muscle force. Age 39 years, sawing time 12,400 h. 
quencies of 60 and $100 \mathrm{~Hz}$, nearly half of the total number of vasospasms. In fig. 4 the mean strength of the vasospasms is presented. The strongest vasospasms were seen at frequencies of $200 \mathrm{~Hz}(\mathrm{p}<0.001)$ and $400 \mathrm{~Hz}(\mathrm{p}<0.01)$ when compared to those at 60 and $100 \mathrm{~Hz}$.

The subjects were classified according to the pulse wave response recorded in the test. The comparison of these groups is presented in table 1 and fig. 5. The actual prevalence of VWF refers to subjects who have had white fingers during the past two years, and the total prevalence of VWF comprises all the Iumberjacks who had sometimes had attacks of white fingers. If more than two years had passed since the last attack of VWF, we considered the disease to have stopped, and these cases are included only in the total prevalence of VWF. In fig. 5 the severity of white fingers is compared according to the traumatic vasospastic disease (TVD) index proposed earlier (18). High index values

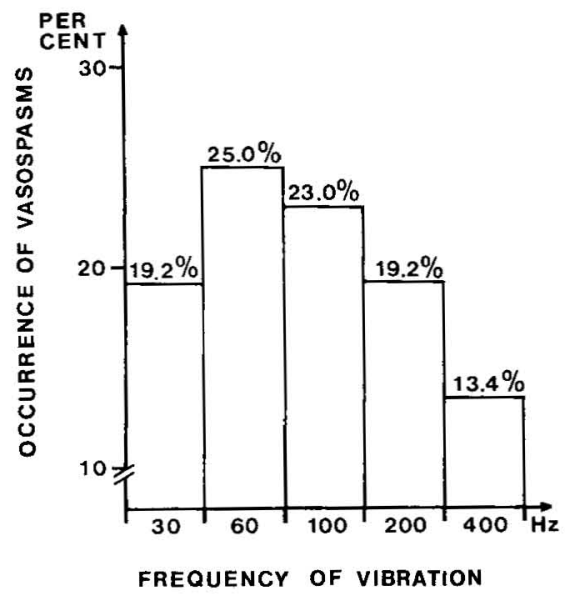

Fig. 3. Percentage of all vasospasms recorded at different frequencies.

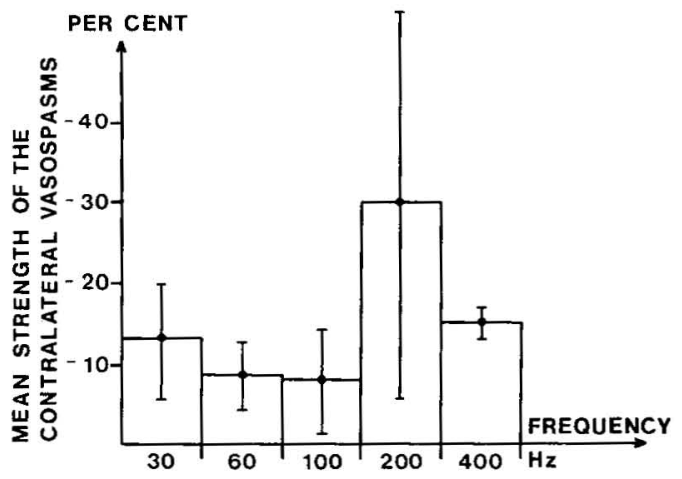

Fig. 4. Mean strength of the contralateral vasospasms at different frequencies. The strength is calculated from the measured vasospasm percentage minus the normal value of $25 \%$. The percentages in the figure represent the means of these values \pm standard deviations.

Table 1. Pulse wave response of the subjects.

\begin{tabular}{lccccc}
\hline Pulse wave response & $\begin{array}{c}\text { Number of } \\
\text { lumber- } \\
\text { jacks }\end{array}$ & $\begin{array}{c}\text { Age } \pm S D \\
\text { (years) }\end{array}$ & $\begin{array}{c}\text { Sawing } \\
\text { time } \\
\pm \mathrm{SD}(\mathrm{h})\end{array}$ & $\begin{array}{c}\text { Actual } \\
\text { prevalence } \\
\text { of VWFa } \\
(\% \%)\end{array}$ & $\begin{array}{c}\text { Total } \\
\text { prevalence } \\
\text { of VWFb } \\
(\%)\end{array}$ \\
\hline $\begin{array}{l}\text { Only vasodilatation } \\
\text { No change }\end{array}$ & 27 & $37.2 \pm 6.7$ & $9,400 \pm 4,600$ & 14.8 & 29.6 \\
$\begin{array}{l}\text { Both vasospasms } \\
\text { and dilatations }\end{array}$ & 11 & $40.9 \pm 7.0$ & $10,700 \pm 2,900$ & 36.4 & 54.5 \\
Only vasospasms & 20 & $41.5 \pm 7.9$ & $10,000 \pm 4,500$ & 45 & 60 \\
\hline
\end{tabular}

a Actual prevalence of vibration-induced white fingers (VWF) = lumberjacks who had had white fingers during the past two years.

b Total prevalence of vibration-induced white fingers (VWF) $=$ all lumberjacks who had had white fingers. 


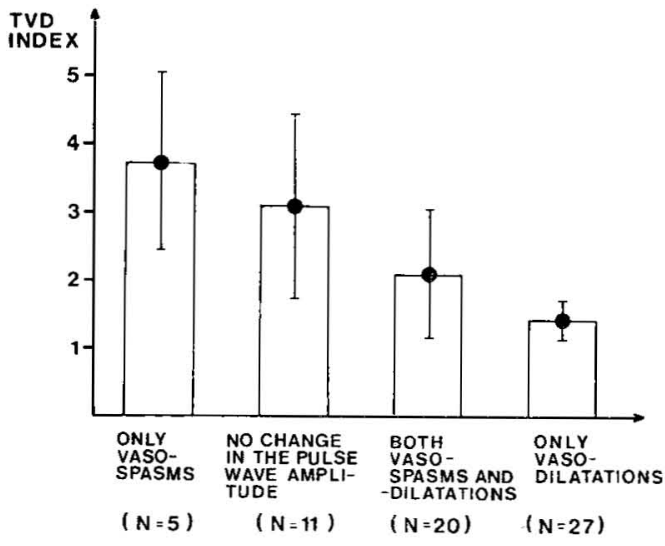

Fig. 5. Severity of vasospastic symptoms according to the traumatic vasospastic disease (TVD) index in different pulse wave groups. Means and standard deviations are given.

represent cases of severe TVD. As seen in fig. 5, those who experienced vasospasms only had the most severe disease. Those who had vasodilatations in the contralateral hand only had the lowest prevalences and mildest disease.

The TVD index of those with only vasodilatation differ significantly from the other groups $(\mathrm{p}<0.05)$. Those with only vasoconstrictions differ significantly from those who had vasodilatations $(p<0.05)$, but not from those who showed no change in the pulse wave amplitude.

\section{DISCUSSION}

According to the original hypothesis of Lewis (8) Raynaud's phenomenon is local and is due to changes in vasoconstrictive nerve endings and increased sensitivity to cold. In Teisinger's review (22) vibration is considered to affect the whole body and disturb the control effects of the central nervous system. The reflexes controlling circulation are stronger during vibration than normally (14).

The effects of vibration on the cardiovascular system were examined by McCutcheon (12). He found large individual variations in the responses to vibration in animals. He also believed that the effects of vibration are partly mediated through the central nervous system. The vasodilatation in the limb was larger in intact animals than in sympathectomized limbs, a finding which also supports the central mechanism's control of the effects of vibration.

In this work we investigated the effects of contralateral vibration and muscle work on the pulse wave. According to Humphreys and Lind (5) the normal response to muscle work is vasodilatation in the working limb. These same authors also describe a contralateral rise in blood pressure during sustained hand grip contractions. In our study we found that contractions in the left hand cause vasodilatation in the skin circulation of the right hand. It can be mediated reflexively or via the temperature regulatory system. The effects of vibration on the ipsilateral hand have been investigated in laboratory measurements with the same plethysmographic method (17), and it was seen that frequencies of 125 and $80 \mathrm{~Hz}$ were the most efficient in causing vasospasms. Only the frequencies $40,80,125,250$, and $400-500$ $\mathrm{Hz}$ were used. In our present experiment we found most vasospasms to occur during the frequencies of 60 and $100 \mathrm{~Hz}$. The strongest vasospasms were seen at $200 \mathrm{~Hz}$. Therefore, these patterns of vasospasm spectrum are quite similar, the efficiency of the causing vasospasm being in the region of 60 to $200 \mathrm{~Hz}$. The occurrence of vasospasms in the contralateral hand supports our theory $(6,19)$ of the central vasoconstrictor reflex being the background of VWF. Also the theory of Hyvärinen suggests that the higher frequencies are more efficient in causing vasospasms, and in this experiment we saw that the strongest vasospasms occurred at frequencies of 200 and $400 \mathrm{~Hz}$, when compared to the frequencies of 30 , 60 and $100 \mathrm{~Hz}$. Nasu (15) found that 100 $\mathrm{Hz}$ was the most efficient frequency in producing a skin temperature decrease, but he investigated only the frequency scale 40 to $120 \mathrm{~Hz}$.

In our study the interval between tests was only $6 \mathrm{~min}$, because we had so many men to test in a short period of time. However, we think $6 \mathrm{~min}$ is long enough 
to recover from exposure to $5 \mathrm{~min}$ of vibration. The effect of this method on muscle force has already been discussed (4). The lumberjacks who experienced vasodilatation only were significantly younger, and they had sawn less than the lumberjacks who had vasoconstrictions only. We do not believe that these differences can explain the results. Anyhow the mean length of exposure to chain saw vibration in all the groups was above the mean latency time $(5,600 \mathrm{~h})$ needed for VWF to develop. Also we do not think that the vasomotoric reactions are so different between lumberjacks 37 and 43 years of age.

Those men who experienced vasoconstrictions only during the contralateral muscle work were also those who had the highest prevalence of VWF and the most severe TVD according to the TVD index (18). Also those who did not show any change in the pulse wave amplitude had a very high prevalence of VWF. Perhaps it is because of a diminished dilatation ability during muscle work. The only group in which VWF was rare and mild was the group of lumberjacks who had vasodilations only, in spite of vibration. Perhaps they fall into the hyposensitive category suggested by Matoba and Kusumoto (11).

These results support the hypothesis of a central vasoconstrictor reflex, as the vibration could cause contralateral vasospasms. Also the strongest vasospasms came at high frequencies. Japanese investigators have examined skin temperature changes during vibratory stimulation. Nasu (15) found that local vibratory stimulus can cause a decrease in the skin temperature, and he considered it to be due to a sympathetic vasoconstrictive reflex. Also Matoba and Kusumoto (11) examined the effects of auditory stimulus on skin temperature. They found that in patients with vibration disease the frequency of Raynaud's phenomenon depends on the level of autonomic nerve activity (measured as skin temperature changes) so that those who were hyperreactive to auditory stimulus were those who had the highest frequency of Raynaud's phenomenon. They concluded that the Raynaud's phenomenon in vibration disease occurs under the con- dition of a disorder of a higher center of the autonomic nervous system than peripheral disturbances. Individually different responses to vibration and muscle work were found, and the result supports the idea that individual factors can explain the differences between subjects who stay healthy and those who soon develop symptoms of vibration disease although the group as a whole has been exposed to similar occupational vibration. Part of the symptoms are due to the central vasoconstrictive reflex, and part of them are probably due to peripheral factors, e.g., neuropathy $(1,2)$.

\section{REFERENCES}

1. ALARANTA, H. and SEPPÄLÄINEN, A.-M. Neuropathy and the automatic analysis of electromyographic signals from vibration exposed workers. Scand. $j$. work environ. \& health 3 (1977) 128-134.

2. ANDREEVA-GALANINA, E. and KARPOVA, N. On degeneration and regeneration of peripheral nerves under the effect of experimental vibration (English summary) Gig. tr. prof. zabol. 13 (1969) 4-7.

3. COFFMAN, J. D. and COHEN, A. S. Total and capillary fingertip blood flow in Raynaud's phenomenon. New engl. j. med. 285 (1971) 5 .

4. FÄRKKILÄ, M. Tärinäsairauden oireet, lihasvoima ja tärinän välittyminen yläraajaan [Symptoms of vibration disease, muscle force in hands and transmission of vibration in the upper extremity] (Työterveyslaitoksen tutkimuksia no. 160). Työterveyslaitos, Institute of Occupational Health, Helsinki 1979. $48 \mathrm{p}$.

5. HUMPHREYS, P. W. and LIND, A. R. The blood flow through active and inactive muscles of the forearm during sustained hand grip contractions. J. physiol. (London) 166 (1963) 120-135.

6. HYVÄRINEN, J. and PYYKKÖ, I. On the etiological mechanism in the traumatic vasospastic disease. Angiologia 7 (1974) $241-246$.

7. HYVÄRINEN, J., PYYKKÖ, I. and SUNDBERG, S. Vibration frequencies and amplitudes in the aetiology of traumatic vasospastic disease. Lancet 1 (1973) 791-794.

8. LEWIS, T. Vascular disorders of the limbs (2nd ed.). MacMillian, London 1949.

9. MAGOS, L. and OKOS, G. Gold dilatation and Raynaud's phenomenon. Arch. environ. health 7 (1963) 402-410.

10. MARSHALL, J., POOLE, E. B. and REYNARD, W. A. Raynaud's phenomenon due to vibrating tools. Lancet 1 (1954) 11511156. 
11. MATOBA, T. and KUSUMOTO, H. The role of higher center of the autonomic nervous system on Raynaud's phenomenon in patients with vibration disease. Presented at the $\mathrm{X}$ international congress of angiology, 1975 .

12. MC CUTCHEON, E. P. Effects of vibration stress on the cardiovascular system of animals: Vibration and combined stress in advanced systems: In: H. E. VON GIERKE (ed.), AGARD conference proceedings no 145. AGARD, London 1975, pp. B 9-1 B 9-13.

13. MENDLOWITS, M. and NAFTCHI, N. The digital circulation in Raynaud's disease. Am. j. cardiol. 4 (1959) $580-584$.

14. NALCA, I. F. Vascular disorders and their pathogenesis in connection with vibration disease (English summary). Sov. med. 34 (1971) 11-14.

15. NASU, Y. Changes of the skin temperature caused by local vibratory stimulation in normals and patients with vibration syndrome. Yonago acta med. 21 (1977) 83-99.

16. OKADA, A., YAMASHITA, T., NAGANO, C., IKEDA, T., YACHI, A. and SHIBATA, S. Studies on the diagnosis and patho- genesis of Raynaud's phenomenon of occupational origin. $B r . j$. ind. med. 28 (1971) $353-357$.

17. PYYKKO, I. A physiological study of the vasoconstrictor reflex in traumatic vasospastic disease. Work environ. health 11 (1974) 118-131.

18. PYYKKO, I. The prevalence and symptoms of traumatic vasospastic disease (TVD) among lumberjacks in Finland: A field study. Work environ. health 11 (1974) $1-14$.

19. PYYKKÖ, I. and HYVÄRINEN, J. The physiological basis of the traumatic vasospastic disease: A sympathetic vasoconstrictor reflex triggered by high frequency vibration. Work environ. health 10 (1973) $36-47$.

20. STEWARD, A. and GODA, D. F. Vibration syndrome. Br. j. ind. med. 27 (1970) 19-27.

21. TAYLOR, W., PEARSON, J., KELL, R. L. and KEIGHLEY, G. D. Vibration syndrome in forestry commission chain saw operators. Br. j. ind. med. 28 (1971) 83-89.

22. TEISINGER, J. Vascular disease disorders resulting from vibrating tools. $J$. occup. med. 14 (1972) 129-133. 